Health \& Medicine | Nestlé

\title{
How does nutrition underpin developmental milestones in toddlers?
}

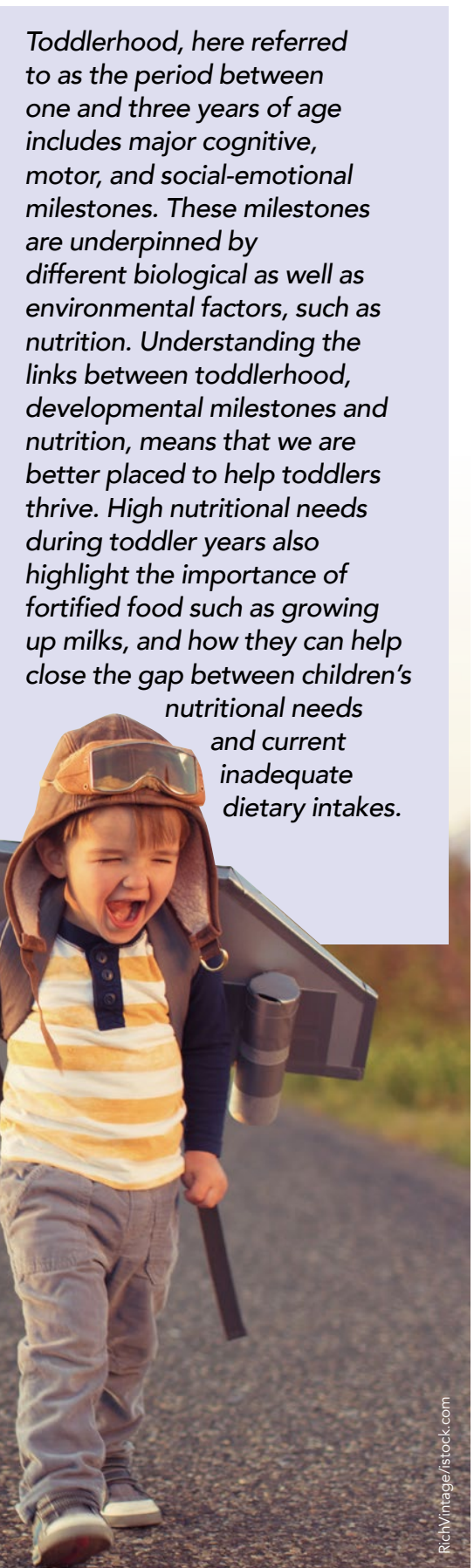
oddlerhood is a crucial stage in
child development. Between birth
and three years, the height of a toddler doubles, and their weight can In addition, by the age of three, the brain reaches $80 \%$ of its adult size (Huelke, 1998). However, this stage often does not receive as much attention from caregivers and healthcare professionals as the first months of life.

During toddlerhood, a child's cognitive skills, social-emotional skills, and sensor

sensory-motor, cognitive and socialemotional skills, providing the building blocks for cell proliferation, DNA synthesis, and neurotransmitter and hos

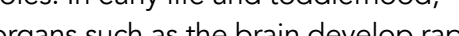
compan to the rest of the body and tis makes them particularly vulnerable to dietary deficiencies.

Lifelong diet quality and dietary patterns are often established during toddlerhood when a child is building foundational

Infographic 1: Contributing factors to child development

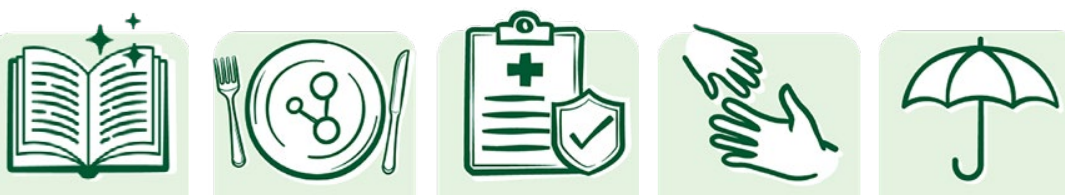

Sensory-motor, cognitive-language and social-emotional skills develop sequentially from simpler motor skills are all developing rapidly (Cusick \& Georgieff, 2016). Directing attention to this stage of life can support the normal development of these skills, setting the child up for optimal development and a greater chance of success throughout their life.

Advancements in these interconnected skill areas are underpinned by rapid functional and structural maturation of the brain, including the creation and strengthening of neural networks. This froctors, as development occurs factors, as development occurs alongside changing nutritional needs. food preferences and healthy eating behaviours, and this stage requires adequate dietary intake (Beckerman et al, 2017). Inadequate intake of the main macronutrients - fats, proteins, micronutrients, such as key vitamins and minerals, can have long-lasting effects on child development, as well as a child's

DEVELOPMENTAL MILESTONES The first years of life are characterised by the achievement of different can be defined as physical skills or (Agost behaviours exhibited by children that -motor, social-emotional, and language-cogn predictable course in infants and childen, as each developmental stage builds upon the skills achieved in previous stages. Understanding healthy development and developmental milestones, and their links with nutrition, is important for health care professionals to be able to recognise developmental delays and optimise healthy development.

At around 12 months, a child begins to walk as a consequence of the developing $\mathrm{m}$ system. Walking of physical and of physical and development. Protein, calcium, magnesium and vitamin $D$ are vital in supporting this development, helping to build normal bones and muscles (EFSA 2008, 2009) which enable a toddler to support their own weight. Once able to explore the environment by themselves, many new possibilities are open to the toddler, and this has subsequent effects on other learning domains, such as socialemotional and cognitive skills. It is around the age of one year that toddlers engage ven more actively with their environme

pointing at objects, returning hugs and corresponding shapes on a board. observed at two years of age. Although a fraction of their adult age, a two-anda-half-year-old has already developed a bone structure that is $50 \%$ of their adult skeleton height (Colson and Dworkin, 1997). Complex motor-skills, such as kicking a ball and walking up and down stairs with support, have been

Understanding healthy development and developmental milestones, and their links with nutrition, is important for health care professionals. mastered. At this age, we continue social skills develop, supported by the maturation of an area of the brain called the limbic system. This means toddlers can better express personality traits, as well as their thoughts and needs. Whilst toddlers at this stage show emotions, they often do not fully know how to control them, as demonstrated by temper tantrums during the infamous 'terrible twos'! This is accompanied by

列

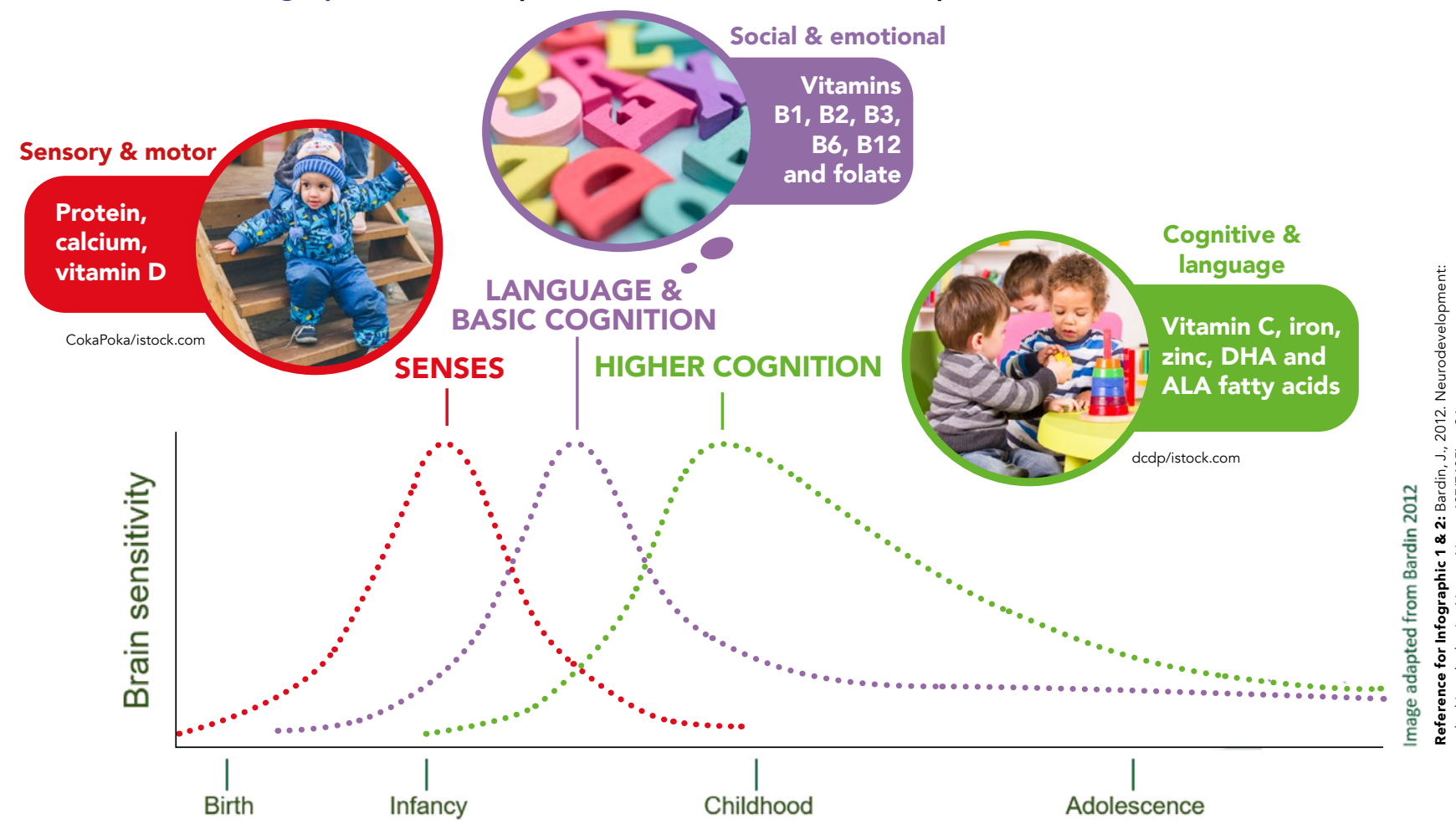


Infographic 3: Examples of micronutrient deficiencies in children

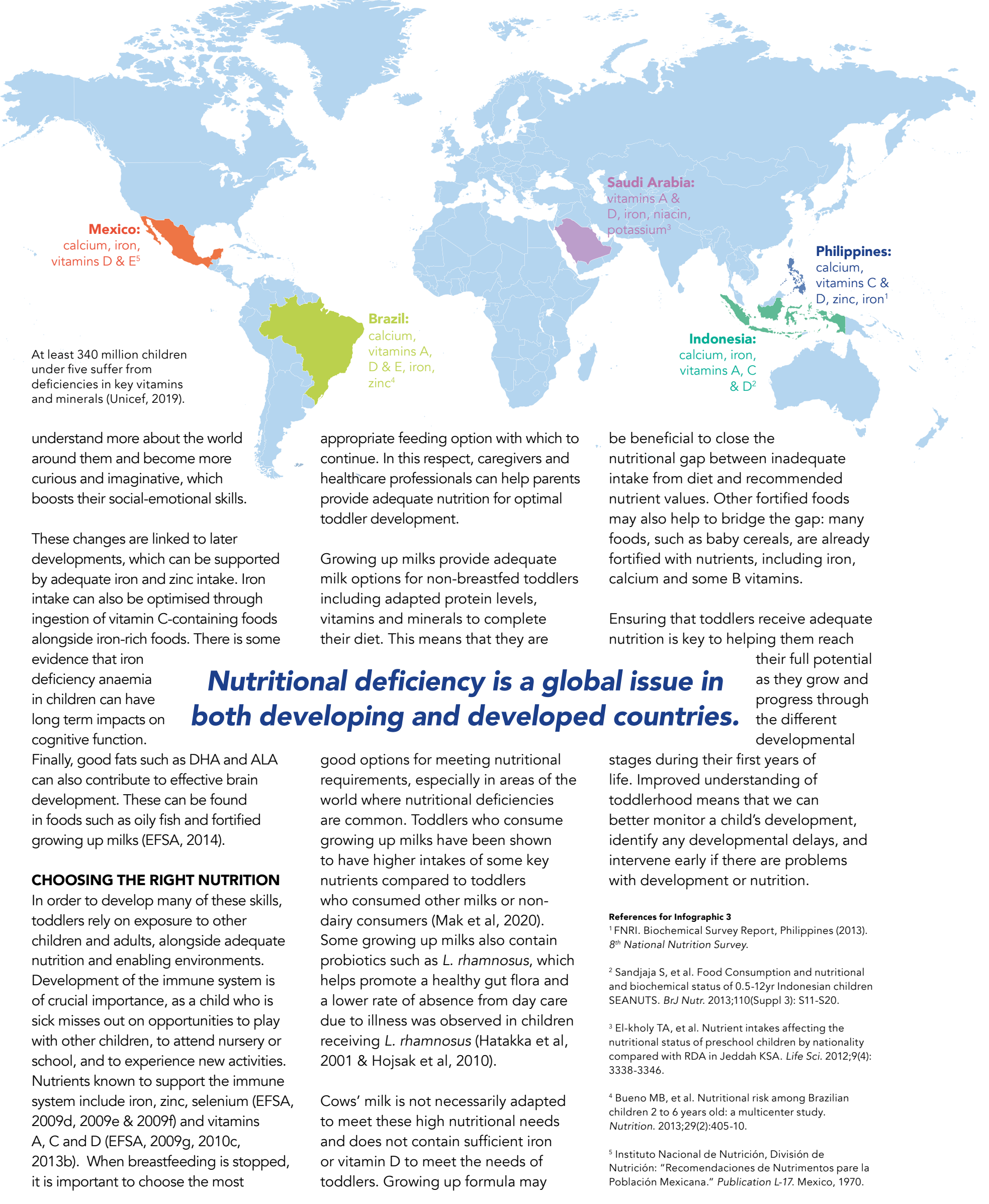

\section{Behind the Research}

Nestlé

Detail

Bio

作

\section{References}

Agosti, M., Tandoi, F., Morlacchi, L., \& Bossi, A. (2017). Nutritional and
metabolic programming during the first thousand days of life. La Pediatria medica e chirurgica : Medical and surgical pediatrics, 39(2), 157. hittps:/l/

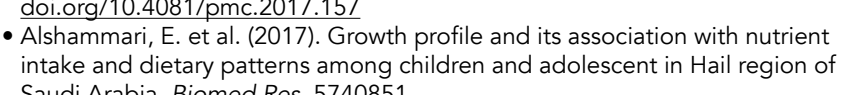

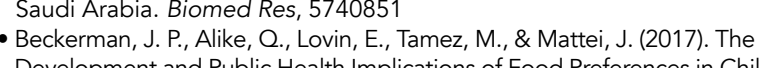
Development and Public Heath Implications of Food Preferenceses in Children.

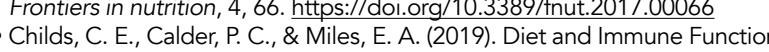
Nutrients, 1 1(8), 1933. hittps://doio. or//10.3390//nu11081933

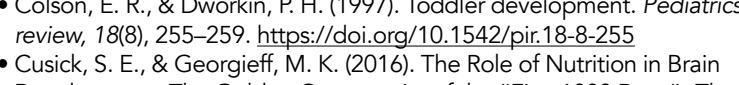

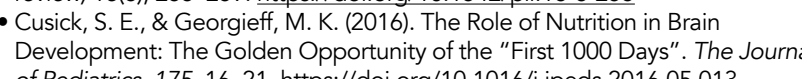
- Dobbing, J. and Sands, J., (1973). Quantitative grouth and development of human brain. Archives of disease in childhood, 48(10), $757-767$

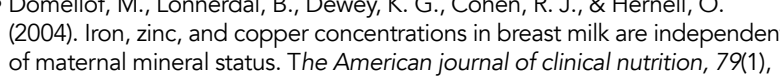

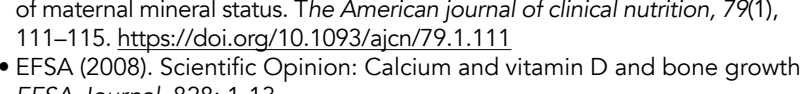
EFSA Journal. 828: 1-13.
- EFSA (2009). Scientific Opinion: Magnesium health related claims. EFSA Journal. 779): 1216.
EFSA (2009). Scientific opinion on the substantiation of health claims related to niacin, and function of the nervous system. EFSA Journal. $7(9): 1222$.
- EFSA (2009c). Scientific Opinion on the substantiation of health claims related to vitamin $B 6$ and protein and glycogen metabolism $(I \mathrm{I} 65,70,71)$, function of
the nervous system (ID 66 ), red blood cell formation (ID 67,72, 186), function

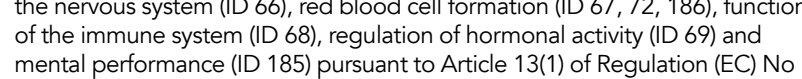
1924/2006. EFSA Journal. 799:1225

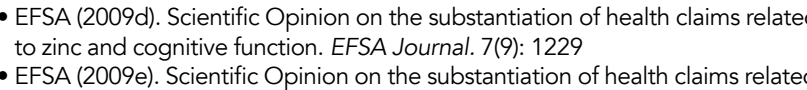
- EFSA (2009). Scientific Opinion on the substantiation of health claims related
to iron and formation of red blood cells and haemoglobin (ID 249, ID 1559),

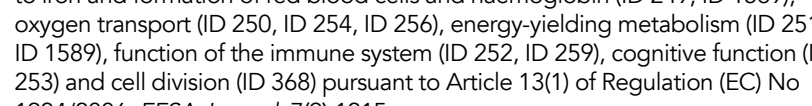
1924/2000. EFSA Journal. 7(9):1215

- EFSA (2009f). Scientific Opinion on the substantiation of health claims related
to selenium and protection of DNA, proteins and lipids from oxidative damage (o selenium and protection of DNA, proteins and lipids from oxidative dama
(ID 277, 283, 286, 1289, 1290, 1291, 1293, 1751), function of the immune

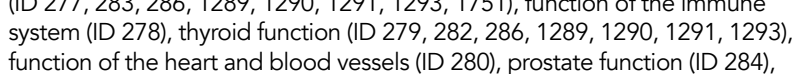
function of the heart and blood vessels (ID 280), prostate function (ID 284),
cognitive function (ID 285) and spermatogenesis (ID 396) pursuant to Article

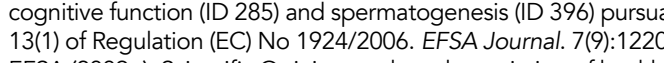

EFSA (2009). Scientific Opinion on the substantiation of health claims related
to vitamin Cand protection of $D$ NA proteins and lipids from

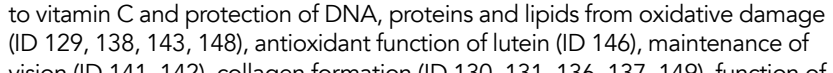

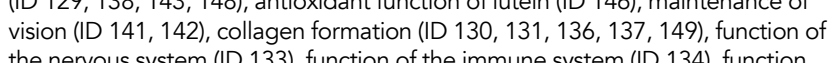
the nervous system (ID 133), function of the immune system (ID 134), function
of the immunes system during and after extreme physical exercise (ID 144), non-

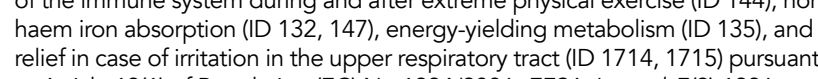

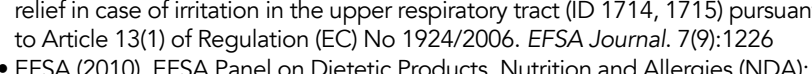
Scientific Opinion on the substantiation of health claims related to vitamin $\mathrm{B}$ $98,100,102,109)$, contribution to normal homocysteine metabolism (ID 96 , $1130,106)$, maintenance of normal bone (ID 1040), maintenance of normal teeth
(ID 104), maintenance of normal hair (ID 104), maintenance of normal skin (ID

\section{Disclaime} Material for healthcare professionals only.
Breastfeeding is best for babies.

104), maintenance of normal nails (ID 104), reduction of tiredness and fatigue
(D 1083), and cell division (ID 212) pursuant to Atricle 13(1) of Regulation (ECC - EFSA (2010b). Scientific OPinion on the substantiation of health claims related to thiamin and reduction of tiredness and fatigue (II 23) and contribution to
normal psychological functions (ID 205) pursuant to Article $13(1)$ of Regulation - EFSA (2010). Scientific Opinion on the substantiation of health claims related o vitamin D and normal function of the immune system and inflammatory maintenance of normal cardiovascular function (ID 159) pursuant to Article 13(1) of Regulation (EC) No 1924/2006. EESA Journal. 8(2): 1468
- EFSA (2013). Scientific Opinion on the substantiation of a heath claim related

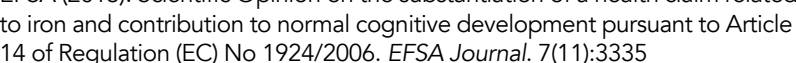
14 of Regulation (ECC) No 1924/2006. EFSA Journal.7(11):3335
EFSA (2013b). Scientific Opinion on the substantiation of a health claim

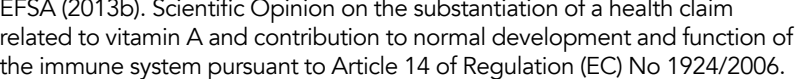
the immune system pursuant to Article 14 of Regulation (EC) No 1924/200
EFSA Journal. $11(7): 3334$ - EFSA (2014). Scientific Opinion: DHA and
develomment. EFSA Journal. 12(10): 3840 .

ENSANUT (Encuesta Nacional de Salud y Nutrición), (2012),
Data on file. Available at https://ensanutinsp. mx Iinformes/ ENSANUT2012ResultadosNacionales pd Hatakka, K., Savilahti, E., Pönkä, A., Meurman, J. H., Poussa, T., Näse, L.,
Saxelin, M., \& Korpela, R. (2001). Efect of long term consumption of probiotic milk on infections in children attending day care centres, do

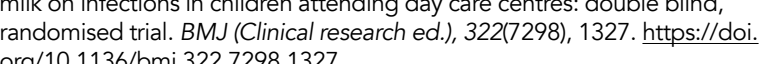

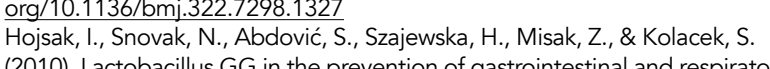
(2010). Lactobacillus $G G$ in the prevention of gastrointestinal and respiratory

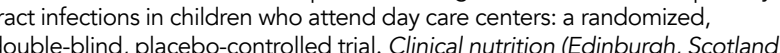
29(3), 312-316. https://doi.org/10.10166/.chu. 2009.09.008 Infants and Children in the Adult World of A Aut Combile SStations of Annual Proceedings / Association for the Advancement of Automotive - Medicine, 42, 93-113.

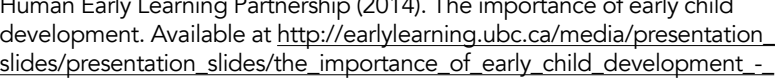

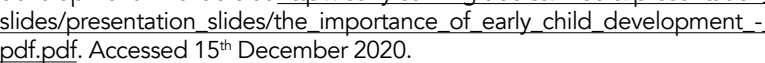
- Huskisson, E., Maggini, S., \& Rut, M. (2007). The influence of micronutrients on cognitive function and performance. The Journal of finternational medical
research, 35(1), $1-19$. https://doiorg/10.1177/14732300703500101 - Instituto Nacional de Nutricióó, ivisión de Nutricicón, 1970.
Recomendaciones de Nutrimentos pare la Población Mexicana. Publication L-17.
- Kennedy D. O. (2016). B Vitamins and the Brain: Mechanisms, Dose and

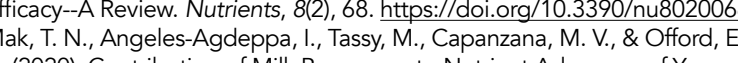
A. (2020). Contribution of Milk Beverages to Nutrient Adequacy of Young
Children and Preschool Children in the Philippines. Nutrients, $122(2), 392$.

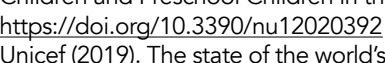

- Uicet (2019). The state of the world's children: Children, food and nutrition
Available at https://www.unicef.org/reports/state-of-worlds-children-2019. Accessed $13^{\text {th }}$ December 2020 -Villena, J., Chiba, E., Tomosada, Y., Salva, S., Marranzino, G., Kitazawa, H., \&
Alvarez, S. (2012). Orally administered Lactobacillus rhamnosus modulates

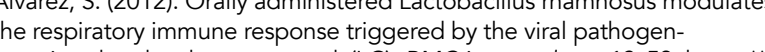
associated molecular pattern polyl:C). BMC immunology, 13, 53. https:// World Health Organization: The WHO Child Growth Standards. Available
at hittpps///wwww.who.int/childgrowth/standards/en Accessed: December
$12^{\text {th }} 2020$ 